\title{
Impact of Fellowship During Single-Incision Laparoscopic Cholecystectomy
}

\author{
Rey Jesús Romero, MD, Jonathan Kirsch Arad, MD, Radomir Kosanovic, MD, Julie Lamoureux, MSc, \\ Anthony Michael Gonzalez, MD
}

\begin{abstract}
Background and Objectives: Minimally invasive surgery fellowship programs have been created in response to advancements in technology and patient's demands. Single-incision laparoscopic cholecystectomy (SILC) is a technique that has been shown to be safe and feasible, but this appears to be the case only for experienced surgeons. The purpose of this study is to evaluate the impact of minimally invasive surgery fellow participation during SILC.
\end{abstract}

Methods: We reviewed data from our experience with SILC during 3 years. The cases were divided in two groups: group 1 comprised procedures performed by the main attending without the presence of the fellow, and group 2 comprised procedures performed with the fellow present during the operation. Demographic characteristics, comorbidities, indication for surgery, total surgical time, hospital length of stay, and complications were evaluated.

Results: The cohort included 229 patients: 142 (62\%) were included in group 1 and 87 (38\%) in group 2. No differences were found in demographic characteristics, comorbidities, and indication for surgery between groups. The total surgical time was $34.4 \pm 11.4$ minutes for group 1 and $46.8 \pm 16.0$ minutes for group $2(P<.001)$. The hospital length of stay was $0.89 \pm 0.32$ days for group 1 and $1.01 \pm 0.40$ days for group $2(P=.027)$. No intraoperative complications were seen in either group. There

Department of General and Bariatric Surgery, Baptist Health South Florida, Miami, FL, USA (Drs. Romero, Arad, Kosanovic, Gonzalez).

Department of Quality and Risk Management, West Kendall Baptist Hospital, Miami, FL, USA (Dr. Lamoureux)

The authors declare no conflict of interest, which may arise from being named as an author on the manuscript.

The authors acknowledge Michelle Gallas and Ignacio Danta, staff at our Center for Research \& Grants.

Address correspondence to: Anthony Michael Gonzalez, MD, Department of General and Bariatric Surgery, Baptist Health South Florida, 7800 SW 87th Ave, Ste B210, Miami, FL 33173, USA. Telephone: (305) 271-9777, Fax: (305) 595-9590, E-mail: anthonyg@baptisthealth.net

DOI: $10.4293 / 108680813 X 13693422520765$

(C) 2014 by JSLS, Journal of the Society of Laparoendoscopic Surgeons. Published by the Society of Laparoendoscopic Surgeons, Inc. were 3 postoperative complications (2.1\%) in group 1 and none in group $2(P=.172)$.

Conclusion: Adoption of SILC during an established fellowship program is safe and feasible. A longer surgical time is expected during the teaching process.

Key Words: Single incision, Laparoscopy, Cholecystectomy, Fellowship, Education, Learning curve.

\section{INTRODUCTION}

After finishing their general surgery residency, surgeons have to choose either to enter general surgical practices or to complete additional surgical training in a formal program. Such formal programs are known as fellowships. This tendency to progressive specialization occurs in response to patient demand and increase in medical knowledge. ${ }^{1}$ The impact of the surgical fellow has been evaluated in different specialties, showing no negative impact in the patients' outcomes. ${ }^{2,3}$ On the other hand, the progressive interest of the surgeons toward minimally invasive surgery has opened the doors to more advanced techniques, such as natural orifice transluminal endoscopic surgery (NOTES), ${ }^{4,5}$ which has, as its main principle, abdominal access through natural orifices such as the mouth or vagina to avoid abdominal wall incisions and make surgery less invasive. However, the challenge of obtaining access through such organs with no spillage and the closure of the luminal incision remain concerns. Advanced skills and complex instruments have limited the use of the procedure, and this has caused many surgeons to look for other alternatives.

Single-incision laparoscopic surgery, or laparoendoscopic single-site surgery, refers to the operative technique in which a surgical procedure is carried out through one incision, typically the umbilicus. In general surgery, this approach has been performed most frequently during cholecystectomy because this procedure is very common and requires relatively fewer surgical skills. Since the first report of single-incision laparoscopic cholecystectomy (SILC) in 1997 by Navarra et al, ${ }^{6}$ several articles have mentioned successful attempts, feasibility, and safety with 
improved cosmetics when performing laparoscopic cholecystectomy through a single incision at the umbilicus. $^{7-10}$ However, this technique requires more advanced surgical skills than conventional laparoscopic cholecystectomy (CLC) and appears to be a good alternative only for experienced laparoscopic surgeons. ${ }^{11}$ In our facilities we have evaluated the feasibility of SILC for $>3$ years. The purpose of this study is to describe our experience with SILC and analyze the impact of minimally invasive surgery fellow participation.

\section{METHODS}

From June 2009 to May 2012, 229 patients underwent SILC. Information regarding demographic characteristics, comorbidities, indication for surgery, complication rate, total surgical time, and hospital length of stay (LOS) were obtained from the surgical records and collected in a database for both quality assurance and subsequent analysis. Inclusion criteria included patients aged between 18 and 89 years, those who required removal of the gallbladder, and those who were treated with the single-incision technique. There were no rigorous exclusion criteria; nevertheless, cases considered "difficult" by the main surgeon, such as patients with severe acute cholecystitis or previous upper abdominal surgery, generally were not offered SILC and were scheduled for CLC. Before the procedure, a detailed explanation about SILC and standard laparoscopic cholecystectomy was provided to every patient, and informed consent was obtained to include both techniques. The cases were divided into two groups: group 1 comprised those cases performed by 1 surgeon with previous experience in conventional laparoscopic surgery ( $>1000$ cases) without the presence of a fellow, and group 2 comprised those cases performed with a clinical surgical fellow and the same attending surgeon. The procedures were performed in two hospitals (Baptist Hospital of Miami and South Miami Hospital) affiliated with Baptist Health System South Florida. The corresponding institutional review board approved the study.

\section{Statistical Analysis}

Descriptive statistics were computed for the whole sample as well as for the two groups as means, standard deviations, and ranges for numerical variables and proportions for categorical variables. With the sample size and the low occurrence rate of the outcomes, this study had only $32 \%$ power to detect a difference of 5 percentage points in rates between the groups on the occurrence of complication. Baseline characteristics of the two groups were com- pared by use of $t$ tests for numerical variables, KruskalWallis tests for ordinal or severely non-normal numerical variables, and $\chi^{2}$ tests for proportions. To compare the groups controlling for potential confounding factors, we used analyses of variance for the surgical time and used a Tobit censored regression for the hospital Los. The ANOVA had $80 \%$ power to defect an average difference of 5.5 minutes, in surgical time between the two groups at a level of significance of .05 . The Tobit regression had 80\% power to detect an average difference of 0.14 days in LOS between the two groups at a level of significance of .05 .

\section{SILC Surgical Technique}

A transverse $2.5-$ to $3-\mathrm{cm}$ incision is made through the umbilicus, and the stalk of the umbilicus is detached from the underlying fascia. A small defect is usually encountered. The abdominal cavity is entered by use of a 5-mmwide/150-mm-long Endopath Xcel Optiview (Ethicon Endosurgery, Blue Ash, Ohio, USA). The abdomen is insufflated to $15 \mathrm{~mm} \mathrm{Hg}$ of pressure with carbon dioxide gas, and two additional 5-mm trocars (Dexide; Covidien, Mansfield, Massachusetts, USA) are placed through the same skin incision but at a different fascial entree, somewhat superior and lateral to the initial trocar. A 5-mm-long bariatric $45^{\circ}$ Stryker laparoscope (Stryker, Kalamazoo, Michigan, USA) is placed through to the center trocar. The gallbladder is grasped with two smooth graspers, and a No. 2-0 Prolene stitch (Ethicon Endo-Surgery, Blue Ash, Ohio, USA) on a Keith needle is passed through the abdominal wall just below the costal margin into the abdominal cavity. The needle and stitch are passed through the mid body of the gallbladder, and the stitch is delivered out of the abdominal cavity. The assistant uses this stitch as the retraction device to elevate the gallbladder. The triangle of Calot is dissected with a blunt roundtip "dolphin" dissector while the infundibulum is retracted laterally. The surgeon uses two hands to operate at all times and uses the instruments in parallel position whereby triangulation is not attempted at any time (Figure 1). Once the critical view is obtained and the cystic duct and artery are dissected, a 5-mm Ethicon clip applier (Ethicon Endo-Surgery) is used to secure these structures and transection is completed with endoscopic shears. The gallbladder is removed from the liver bed by electrocautery. Once it has been separated from the liver, the second assistant, using the Prolene stitch, suspends the gallbladder. Next, the middle 5-mm-wide/150-mmlong Optiview trocar is removed. The opening is expanded with a Kelly clamp, and a 10-mm Endopouch specimen retrieval bag system (Ethicon Endo-Surgery) is 


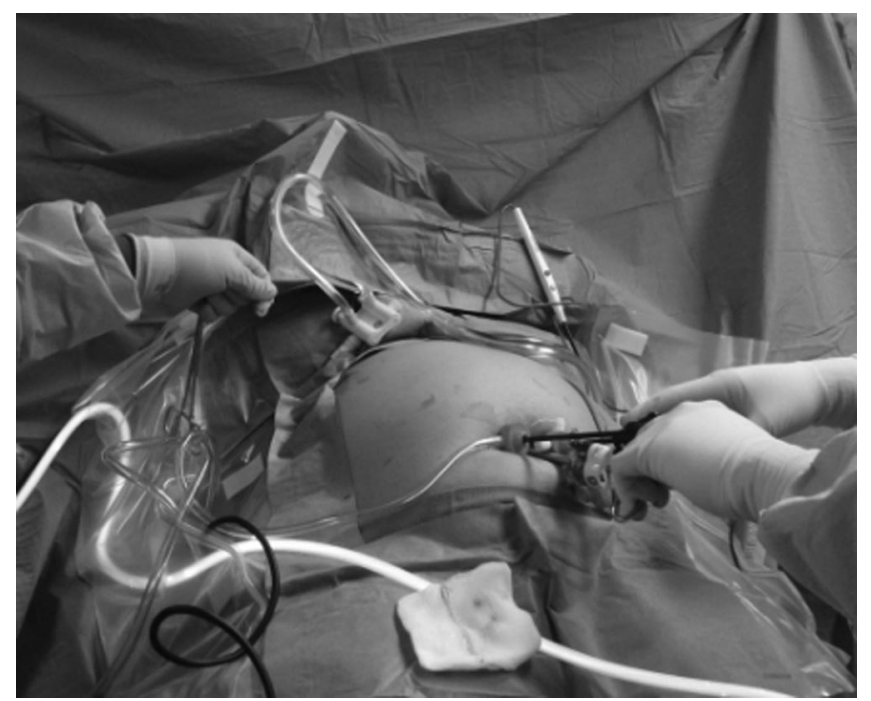

Figure 1. Position of second assistant retracting gallbladder with Prolene stitch (left) and surgeon maneuvering instruments in parallel position (right).

placed intra-abdominally. The gallbladder is dropped into the bag and extracted from the abdomen. The fascial opening is closed with No. 0 Vicryl sutures (Ethicon EndoSurgery). The umbilicus is reattached to the fascia with No. 3-0 Monocryl (Ethicon Endo-Surgery), and the skin is closed. The wound is dressed with Dermabond Advanced Topical Skin Adhesive (Ethicon Endo-Surgery).

\section{RESULTS}

This study included 229 patients; among them, there 181 women (79\%) and 48 men (21\%). The mean age was $45.2 \pm 14.6$ years (range, $18-87$ years), the mean body mass index (BMI) was $29.3 \pm 5.9 \mathrm{~kg} / \mathrm{m}^{2}$ (range, $16.4-51.4$ $\mathrm{kg} / \mathrm{m}^{2}$ ), the mean American Society of Anesthesiologists (ASA) score was $1.73 \pm 0.67$ (range, 1-3), the mean surgical time was $39.1 \pm 14.6$ minutes (range, 13-102 minutes), and the mean hospital LOS was $0.93 \pm 0.36$ days (range, $0.5-4$ days). We observed 3 complications (1.3\%) in this series. The follow-up in our series was 1 to 4 weeks.

Group 1 included 142 cases (62\%) performed by the same attending surgeon without a fellow, and group 2 included 87 cases (38\%) performed by two different fellows with the one attending surgeon present. The descriptive statistics for the two groups are given in Table 1. The groups were similar in age $\left(\mathrm{t}_{227 d f}=1.882, P=.061\right)$, gender distribution $\left(\chi_{1 d f}^{2}=0.171, P=.679\right)$, BMI $\left(\mathrm{t}_{226 d f}=1.225\right.$, $P=.222$ ), and rates of other chronic systemic conditions (Table 1). Group 2 had significantly higher ASA scores than group $1\left(\chi^{2}{ }_{1 d f}=4.446, P=.035\right)$.
Differences in outcomes for both group 1 and group 2 are shown in Table 2. The mean surgical time was significantly longer for group 2 compared with group $1\left(\mathrm{t}_{139.4 d f}=6.296\right.$, $P<.001$ ). Figure 2 illustrates this trend in surgical times. We ran an analysis of variance to test this difference in time controlling for ASA scores. Even when we controlled for ASA scores, the marginal means of surgical time were significantly higher for group $2\left(F_{1,225}=40.52, P<.001\right)$. The hospital LOS was significantly longer for the patients in group 2 compared with those in group $1\left(\chi_{\mathrm{KW} 1 d f}^{2}=\right.$ 4.919, $P=.027$ ). To determine whether the hospital LOS was in fact significantly different between the groups after controlling for the difference in ASA scores, we ran a Tobit censored regression. The presence of the ASA score was not significant $(t=0.67$ and $P=.503$ for a score of 2 and $t=0.51$ and $P=.609$ for a score of 3 compared with a score of 1) in predicting the hospital LOS. None of the other outcomes showed significant differences between the two groups.

Complications were seen in 3 cases, all observed in group 1: a 23-year-old woman who was rehospitalized because of an abdominal wall hematoma that required drainage but had no major surgery; a 35-year-old woman who was readmitted 3 days after surgery for intractable nausea and vomiting and was treated medically; and a 29-year-old woman who presented with a retained common bile duct stone that was extracted by endoscopic retrograde cholangiopancreatography and was discharged uneventfully. The rate of occurrence of complications was not significantly different between the two groups $\left(\chi_{1 d f}^{2}=1.862\right.$, $P=.172$ ).

\section{DISCUSSION}

In recent years SILC has become a popular technique for performance of cholecystectomy. Multiple series and randomized trials, as well as a few meta-analyses, have evaluated its safety and efficacy. Some authors have concluded that SILC is a good alternative with excellent results, but others argue that this technique has some disadvantages when comparing with CLC. A recent metaanalysis of 9 randomized trials comparing SILC versus CLC reported significantly a longer surgical time with SILC. ${ }^{12}$ In addition, more major complications, wound-related complications, and port-site hernia were observed in the SILC group, but no statistical difference was found in such variables. In the meta-analysis, hospital LOS and pain score yielded similar results in both groups and the only parameter that favored SILC was the cosmetic outcome. Other possible advantages of SILC are reduced parietal 
Table 1.

Differences in Demographic Characteristics, Comorbidities, and Indication for Surgery for Both Group 1 and Group 2

\begin{tabular}{|c|c|c|c|c|}
\hline & $\begin{array}{l}\text { Group } 1 \text { (attending only) } \\
(n=142)\end{array}$ & $\begin{array}{l}\text { Group } 2 \text { (with fellow) } \\
(\mathrm{n}=87)\end{array}$ & Test & $\begin{array}{l}P \\
\text { Value }\end{array}$ \\
\hline \multicolumn{5}{|l|}{ Demographic characteristics } \\
\hline Female & $111(78.2 \%)$ & $70(80.5 \%)$ & $\chi_{1 d f}^{2}=0.171$ & .679 \\
\hline Male & $31(21.8 \%)$ & $17(19.5 \%)$ & & \\
\hline Mean age $(y)$ & $43.8 \pm 14.2($ range, $19-84)$ & $47.5 \pm 15.0($ range, $18-87)$ & $t_{227 d f}=1.882$ & .061 \\
\hline \multicolumn{5}{|l|}{ Comorbidities } \\
\hline Mean BMI $\left(\mathrm{kg} / \mathrm{m}^{2}\right)$ & $28.9 \pm 5.5($ range, $18.7-41.9)$ & $29.9 \pm 6.1($ range, $16.4-51.4)$ & $t_{226 d f}=1.225$ & .222 \\
\hline Mean ASA score & $1.65 \pm 0.64$ & $1.86 \pm 0.68$ & $\chi_{1 d f}^{2}=4.446^{\mathrm{a}}$ & .035 \\
\hline Diabetes mellitus & $8(5.6 \%)$ & $3(3.4 \%)$ & $\chi_{1 d f}^{2}=0.576$ & .448 \\
\hline Hypertension & $22(15.5 \%)$ & $16(18.4 \%)$ & $\chi_{1 d f}^{2}=0.327$ & .567 \\
\hline Cardiovascular disease & $6(4.2 \%)$ & $4(4.6 \%)$ & $\chi_{1 d f}^{2}=0.021$ & .885 \\
\hline Hypothyroidism & $8(5.6 \%)$ & $5(5.7 \%)$ & $\chi_{1 d f}^{2}=0.001$ & .975 \\
\hline $\begin{array}{l}\text { Gastroesophageal reflux } \\
\text { disease }\end{array}$ & $20(14.0 \%)$ & $15(17.2 \%)$ & $\chi_{1 d f}^{2}=0.401$ & .527 \\
\hline Pulmonary disease & $6(4.2 \%)$ & $9(10.3 \%)$ & $\chi_{1 d f}^{2}=3.294$ & .069 \\
\hline $\begin{array}{l}\text { Previous abdominal } \\
\text { surgery }\end{array}$ & $52(36.6 \%)$ & $38(43.6 \%)$ & $\chi_{1 d f}^{2}=1.127$ & .288 \\
\hline $\begin{array}{l}\text { Previous upper } \\
\text { abdominal surgery }\end{array}$ & $5(3.5 \%)$ & $6(6.9 \%)$ & $\chi_{1 d f}^{2}=1.393$ & .238 \\
\hline \multicolumn{5}{|l|}{ Indication for surgery } \\
\hline $\begin{array}{l}\text { Symptomatic gallbladder } \\
\text { stones }\end{array}$ & $110(77.4 \%)$ & $64(73.5 \%)$ & $\chi_{4 d f}^{2}=8.991$ & .061 \\
\hline Acute cholecystitis & $11(7.7 \%)$ & $4(4.6 \%)$ & & \\
\hline Biliary dyskinesia & $10(7.0 \%)$ & $14(16.0 \%)$ & & \\
\hline Polyps & $8(5.6 \%)$ & $1(1.1 \%)$ & & \\
\hline $\begin{array}{l}\text { Choledocholithiasis/biliary } \\
\text { pancreatitis }\end{array}$ & $3(2.1 \%)$ & $4(4.6 \%)$ & & \\
\hline
\end{tabular}

trauma and faster recovery; nevertheless, these probable advantages of SILC are not well accepted, and most surgeons perform SILC just because of its better esthetic results.

In our series of cases, we did not have any complications during the intraoperative course, but we observed 3 postoperative complications (1.3\%). The mean surgical time was 39.2 minutes. Our results in terms of complication rate appear to be lower than those of other studies in the literature; in addition, our reported experience shows a shorter total surgical time than other series. In a systematic review of 29 studies that included 1166 SILCs, Antoniou et $\mathrm{al}^{13}$ reported a complication rate of $6.1 \%$ and a mean surgical time of 70.2 minutes. Markar et $\mathrm{al}^{14}$ in a recent meta-analysis reported a complication rate of $10.2 \%$ and a range from 41 to 109 minutes for surgical time. Finally, in a large systematic review including 49 studies (2336 patients), Hall et $\mathrm{al}^{15}$ found a complication rate of $7.3 \%$ and a range from 40 to 113 minutes for mean surgical time. Several factors could influence our results compared with other articles in the literature. These include technical factors, instrumentation, and patient selection. Selection bias could influence these results because in our series, we selected patients with low BMI and elective surgery for single-incision laparoscopic surgery and avoided selecting patients with severe inflammation and/or dense intra-abdominal adhesions. In this report we aimed at evaluating the impact of the fellow in the performance of SILC. Our fellowship program began in December 2010; therefore solely the attending 
Table 2.

Differences in Outcomes for Both Group 1 and Group 2

\begin{tabular}{|c|c|c|c|c|}
\hline Outcome & $\begin{array}{l}\text { Group } 1 \text { (attending only) } \\
(\mathrm{n}=142)\end{array}$ & $\begin{array}{l}\text { Group } 2 \text { (with fellow) } \\
(\mathrm{n}=87)\end{array}$ & Test & $P$ Value \\
\hline Mean surgical time (min) & $34.4 \pm 11.4($ range, $13-73)$ & $46.8 \pm 16.0($ range, $22-102)$ & $t_{139.4 d f}=6.296^{\mathrm{a}}$ & $<.001$ \\
\hline Mean hospital length of stay (d) & $0.89 \pm 0.32($ range, $0.5-2)$ & $1.01 \pm 0.40($ range, $0.5-4)$ & $\chi_{1 d f}^{2}=4.919^{\mathrm{b}}$ & .027 \\
\hline Simultaneous procedures & $5(3.5 \%)$ & $3(3.4 \%)$ & $\chi_{1 d f}^{2}=0.001$ & .977 \\
\hline Cholangiogram & $11(7.7 \%)$ & $13(14.9 \%)$ & $\chi_{1 d f}^{2}=0.044$ & .834 \\
\hline $\mathrm{ERCP}^{\mathrm{c}}$ & $4(2.8 \%)$ & $4(4.6 \%)$ & $\chi_{1 d f}^{2}=0.507$ & .476 \\
\hline Intraoperative complications & 0 & 0 & & \\
\hline Postoperative complications & $3(2.1 \%)$ & 0 & $\chi_{1 d f}^{2}=1.862$ & .172 \\
\hline
\end{tabular}

${ }^{\text {a }}$ Satterthwaite correction for unequal variances.

${ }^{\mathrm{b}}$ Kruskal-Wallis rank test.

${ }^{\mathrm{c}} \mathrm{ERCP}=$ endoscopic retrograde cholangiopancreatography.

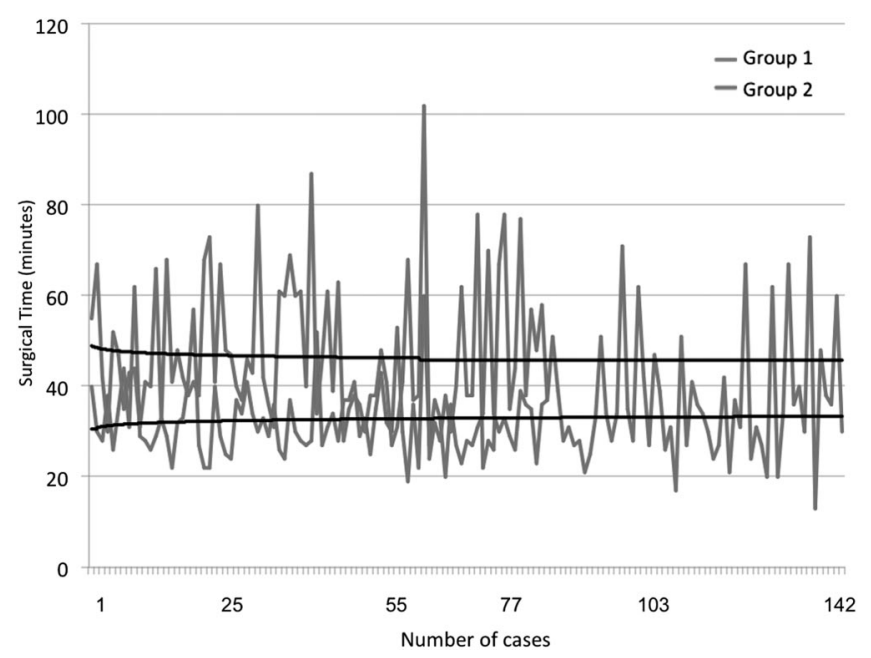

Figure 2. Differences between group 1 and group 2 in surgical time and learning curve.

surgeon performed all cases before that date. The role of the fellow in minimally invasive surgery during our fellowship progresses throughout the year. The fellow's role and participation in SILC begins with observation initially, progresses to holding the camera to understand the collisions that occur during SILC, and then finally concludes in the fellow performing a portion of the SILC (suture placement in gallbladder, dissection, application of clips, removal of gallbladder from liver bed). In addition, education regarding cholecystectomy through a multiport or single incision is provided during the monthly core conferences.

In all the cases described in this series, the surgical attending was present during the entire procedure. It was noted in this study that group 1 and group 2 were similar in terms of demographic characteristics, comorbidities, and indication for surgery (Table 1). The ASA score showed a statistical difference $(P=.035)$, but after we controlled for ASA score, the differences observed in surgical time and hospital LOS were still significant. Intraoperatively, the groups were also similar in terms of number of cholangiograms $(P=.834)$ and concurrent procedures $(P=$ .172) performed. Endoscopic retrograde cholangiopancreatography $(P=.476)$ was needed in each group at similar rates. The 3 complications in this series were observed only in group 1. Factors such as the type of patient, technical details, or unrecognized events may have influenced this tendency; however, no statistical difference was found when the groups were compared $(P=.171)$.

Total surgical time showed statistical differences between groups $(34.4 \pm 11.4$ minutes for group 1 and $46.8 \pm 16.0$ minutes for group $2, P<.001)$. We attribute this difference to the presence of the fellow. In Figure 2 we show differences in surgical time for groups 1 and 2 based on the number of cases. This graph reflects that surgical time in group 1 did not decrease during the procedures performed; instead, it remained similar during the entire period of evaluation. This straight curve differs from others articles reported in the literature where an appreciable drop in surgical time is shown as experience is gained. For example, Hernandez et $\mathrm{al}^{16}$ in a study that included 150 cases, mentioned that after 75 cases, the operative time significantly decreased, and Culp et $\mathrm{al}^{17}$ showed a decline only after 5 cases. In our study, when we compare learning curves, a similar pattern is observed in both groups: the curve for group 1 lies slightly below and parallel to 
that for group 2 (Figure 2), implying the longer surgical time for group 2. Differences in surgical time were also observed by Joseph et $\mathrm{al}^{18}$ in a study — evaluating learning curves between chief residents during SILC-documenting that when the attending functioned as a main surgeon, the mean surgical time was shorter than when the resident was present.

Finally, the hospital LOS showed significant differences between groups, favoring group 1 ( $0.89 \pm 0.32$ days vs $1.01 \pm 0.40$ days, $P=.027$ ). Because in this series most of the patients were discharged the next morning after the procedure, we do not believe that this is related to the presence of the fellow or the prolonged surgical time.

In conclusion, we show that adoption and performance of SILC during an established fellowship program are safe and feasible, even though a longer surgical time was observed when fellows were present. Given the complexity of this procedure combined with the inexperience of a surgeon in training, the attending surgeon should actively participate in all cases. If these recommendations are followed, a low complication rate as reported here should be encountered.

\section{References:}

1. Stitzenberg KB, Sheldon GF. Progressive specialization within general surgery: adding to the complexity of workforce planning. J Am Coll Surg. 2005;201:925-932.

2. Nandivada P, Lagisetty KH, Giles K, et al. The impact of endovascular procedures on fellowship training in lower extremity revascularization. J Vasc Surg. 2012;55:1814-1820.

3. Agrawal S. Impact of bariatric fellowship training on perioperative outcomes for laparoscopic Roux-en-Y gastric bypass in the first year as consultant surgeon. Obes Surg. 2011;21:1817-1821.

4. Lehmann KS, Ritz JP, Wibmer A, et al. The German registry for natural orifice translumenal endoscopic surgery: report of the first 551 patients. Ann Surg. 2010;252:263-270.

5. Dallemagne B, Perretta S, Allemann P, Asakuma M, Marescaux J. Transgastric hybrid cholecystectomy. Br J Surg. 2009;96: 1162-1166.

6. Navarra G, Pozza E, Occhionorelli S, Carcoforo P, Donini I. One-wound laparoscopic cholecystectomy. Br J Surg. 1997;84:695.
7. Chang SK, Tan SS, Kok YO. Early experience in single-site laparoscopic cholecystectomy. Singapore Med J. 2012;53:377380 .

8. Ceci F, Di Grazia C, Cipriani B, et al. Cholecystectomy by single incision laparoscopic surgery (SILS): early experience and technique standardization. G Chir. 2012;33:280-284.

9. Karim MA, Ahmed J, Mansour M, Ali A. Single incision vs. conventional multiport laparoscopic cholecystectomy: a comparison of two approaches. Int J Surg. 2012;10:368-372.

10. Choi SH, Hwang HK, Kang CM, Lee WJ. Single-fulcrum laparoscopic cholecystectomy: a single-incision and multi-port technique. ANZ J Surg. 2012;82:529-534.

11. Wang Z, Huang X, Zheng Q. Single-incision versus conventional laparoscopic cholecystectomy: a meta-analysis. ANZ J Surg. 2012;82:885-889.

12. Garg P, Thakur JD, Garg M, Menon GR. Single-incision laparoscopic cholecystectomy vs. conventional laparoscopic cholecystectomy: a meta-analysis of randomized controlled trials. J Gastrointest Surg. 2012;16:1618-1628.

13. Antoniou SA, Pointner R, Granderath FA. Single-incision laparoscopic cholecystectomy: a systematic review. Surg Endosc. 2011;25:367-377.

14. Markar SR, Karthikesalingam A, Thrumurthy S, Muirhead L, Kinross J, Paraskeva P. Single-incision laparoscopic surgery (SILS) vs. conventional multiport cholecystectomy: systematic review and meta-analysis. Surg Endosc. 2012;26:1205-1213.

15. Hall TC, Dennison AR, Bilku DK, Metcalfe MS, Garcea G. Single-incision laparoscopic cholecystectomy: a systematic review. Arch Surg. 2012;147:657-666.

16. Hernandez J, Ross S, Morton C, et al. The learning curve of laparoendoscopic single-site (LESS) cholecystectomy: definable, short, and safe. J Am Coll Surg. 2010;211:652-657.

17. Culp BL, Cedillo VE, Arnold DT. Single-incision laparoscopic cholecystectomy versus traditional four-port cholecystectomy. Proc (Bayl Univ Med Cent). 25:319-323, 2012 Oct.

18. Joseph M, Phillips M, Farrell TM, Rupp CC. Can residents safely and efficiently be taught single incision laparoscopic cholecystectomy? J Surg Educ. 2012;69:468-472. 